Argumentation in religious education in England: An analysis of Locally Agreed Syllabuses

Jessica CHAN https://orcid.org/0000-0002-7523-3058

Nigel FANCOURT https://orcid.org/0000-0002-0822-6157

Liam GUILFOYLE https://orcid.org/0000-0002-3736-0339 


\begin{abstract}
The importance of developing students' ability to argue effectively is generally recognised across the curriculum, however what this means within religious education has not been thoroughly investigated. We explore this issue first through an initial review of both wider philosophical and curriculum literature on argumentation, notably Toulmin's work, and then a review of relevant research within religious education. We then describe our curriculum analysis, addressing three research questions focusing on the frequency, purpose and conceptualisation of argumentation, though a mixed-methods curriculum analysis of locally agreed syllabi across England (LASs). A quantitative analysis of frequency in thirty-five LASs showed that although argumentation was never mentioned, other cognates were always present. A detailed qualitative analysis of six LASs showed that its purpose was linked to personal expression within democratic participation, and epistemic and empathetic flexibility. Using Toulmin's model of argumentation as a frame, it is generally conceptualised around the elements of claim, evidence and rebuttal, but the precise nature of evidence, warrant and backing are not explicit, especially as the field-dependent elements are unspecified. The implications of these findings for both general conceptualisations of argumentation and curriculum development within religious education are outlined.
\end{abstract}

\title{
Keywords
}

Argumentation; reasoning; religious education; curriculum 


\section{Argumentation in religious education in England: An analysis of Locally Agreed}

\section{Syllabuses}

\section{Introduction}

Religious education (RE) in England has long included the aims of promoting the examination of claims made by different religions (and worldviews), encouraging students to interpret and evaluate these claims, and to formulate and refine their own opinions. Philosophically, this skill is termed argumentation (Toulmin 1958; Walton 1996) and is found across the curriculum (Joshi 2016; Staples, Newton, and Anagnostopoulos 2016). Thus, science education research has examined curriculum and classroom approaches to argumentation (Erduran and JimenezAleixandre 2008; Zembal-Saul et al. 2002; Zohar and David, 2008), generating complex models of how argumentation works in school science. As part of a wider research project examining argumentation across RE and science (Erduran et al. 2019), we wished to explore the place of argumentation in current research and curriculum documents in RE. However, arguably developing any reasoning ability requires a systematic theoretical model, otherwise pedagogical activities aiming to foster it may result in ineffectual participation and outcomes in learning, so we must explore what is meant by argumentation.

\section{Argumentation across the curriculum}

Argumentation, simply defined, is the coordination of evidence and reasons to support claims or the process of engaging with or generating arguments (Toulmin 1958). An 'argument', in common parlance, might be thought of as a quarrel between two or more individuals in conflict. However, this is not the usage of the word that concerns us. An argument is essentially an account of reasoning or a 'reasoned discourse'; a justification for a claim which is supported by evidence and reasons (Billig 1996). In this sense, arguments have an epistemic value, 
providing justification for knowledge, whether as individual expressions in social dialogues, or internal dialogues (Kuhn 1993).

In educational policy, where 'higher order' or 'critical' thinking skills are valued outcomes (OECD 2018), the importance of argumentation becomes apparent, and has been explored across many subjects, including science, mathematics, literature, and history (Staples, Newton, and Anagnostopoulos 2016; Goldman, Ko, Greenleaf, and Brown 2018). Generally, there are two broad goals for engaging in argumentation. Firstly, there is a desire for students of a subject/discipline to know more than just substantive content knowledge, but also to know about the subject's intellectual processes, including 'how claims are justified and validated, and what doing and engaging in discourse in the field entails' (Ball and McDiamid 1990, 438). Secondly, one function of schooling is developing students to be sufficiently literate to participate in democratic society as future citizens (Gutmann and Ben-Porath 2015); and the teaching of argumentation can serve this important function.

Each discipline or subject will have unique features of argumentation that reflect its epistemology (Goldman, Ko, Greenleaf, and Brown 2018), and the criteria for a convincing argument will vary between different disciplines. Toulmin (1958) referred to this as the 'fielddependent' features of an argument, while also recognising the existence of 'field-invariant' elements. While there are other theoretical underpinnings in argumentation in education (e.g. Walton 1996), Toulmin's definition of an argument has been extensively used in science (Erduran, Simon, and Osborne 2004), history (Pontecorvo and Girardet 1993), and English (Rex, Thomas, and Engel 2010). The ensuing pattern is often referred to as Toulmin's Argument Pattern, or TAP (Figure 1). 
[insert Figure 1]

TAP demonstrates the relations between an argument's different potential components (see Toulmin 1958). Arguments will need, at very least, a claim. This is the conclusion or assertion that is at their core. All other elements of the argument are present to support, refute, or qualify this claim. Data (or evidence) are what one presents to support the claim, including ethical, philosophical or legal justifications and not simply empirical evidence. The warrant is in essence the reason why data/evidence are relevant to the claim. Sometimes a warrant is implicit, but it is a necessary 'authorising step' connecting the data/evidence to the claim. Backing further supports or provides assurances about the authority of the warrant. A rebuttal may be a challenge to elements of the argument (i.e. to the claim, the data, the warrant, or the backing) or an acknowledgement of potential weaknesses within the argument. Finally, a qualifier to a claim provides an indication of the degree of certainty in the claim (e.g. the claim is 'probably' true, or true under certain conditions).

\section{Argumentation in religious education}

In reviewing $\mathrm{RE}$ research on argumentation and reasoning more widely, three main themes developed. First, there is considerable attention to the potential underlying academic disciplines of the subject, which would determine the forms of argumentation. The broad trajectory in England has been a rejection of theology within pluralistic RE - though not within faith schools (Cush 1999) - and its replacement by, variously, religious studies (Smart 1989), social sciences (Jackson 1997) or philosophy (Hookway 2002; Hella and Wright 2009). However, some have reappraised this rejection, arguing that theology was misrepresented and has developed in the meantime (Reed, Freathy, Cornwall, and Davis 2013; Freathy and John 2019), especially as argumentation is valued within many religions, for example Judaism (Shulman 2008), Islam (Wallbridge 2011), Buddhism (McClintock 2010) and Christianity (Helm 2003). Some have 
expressed concern about the proliferation of multiple disciplinary perspectives (e.g. Teece 2011; Conroy, Lundie, and Baumfield 2012; Conroy et al. 2013), especially when these are not grounded within a faith tradition (Gearon 2013), though others have embraced an explicit multidisciplinary approach, such as the 'RE-Searchers' project (Freathy et al. 2017). Generally, these debates mean that what counts as a disciplinary claim, warrant or evidence are not settled.

Next, some research focuses on the process of argumentation, or on wider reasoning strategies. Gottlieb (2001) applied Toulmin's model in Jewish education (see also Gottlieb and Mandel Leadership Institute 2007), and particularly sought to critique Goldman's Piagetian claim that students' ability to reason in RE was developmentally fixed (Goldman 1965). Recently, several German-speaking researchers have investigated the argumentation in RE, usually in connection with science and religion debates, e.g. Bioethics (Fuchs 2009; Schmidt, Rothgangel, and Grube 2015; Schmidt, Gruber, and Rothgangel 2017), and Creation and Evolution (Basel, Harms, and Prechtl 2013; Basel et al. 2014; Weiss 2016), and are often across both subjects, drawing on the theorists set out above - or on German-language alternatives, e.g. Weiss's (2016) use of Keinpointner (1983). One difference between English and German-language research is that RE in German-speaking countries is largely confessional, and therefore rooted in a theological tradition, and these studies lie within a broader field of research on students' and teachers' attitudes to religion and science, which implicitly invokes argumentation, including studies of ‘epistemic literacy' (Pearce, Stones, Reiss, and Mujtaba 2019), and 'epistemic insight' (e.g. Billingsley et al. 2013; Billingsley, Riga, Taber, and Newdick 2014; Hanley, Bennett, and Ratcliffe 2014; see also Astley and Francis 2010). Other UK-based research has drawn attention to the value of generic intellectual strategies in RE, such as 'thinking skills' (e.g. Baumfield 1996), 'gifted and talented' strategies (e.g. Simpson 2012), or 'Philosophy for Children' (Thwaites 2005), but these developments have not been advanced, perhaps because of the lessening importance of the national curriculum in England. 
The third theme is the role of instructional techniques and classroom strategies in fostering argumentation. Classroom discussion is much considered, though generally focusing on impartiality (e.g. Jackson and Everington 2017) and its function as a 'safe forum' for democratic and/or inter-religious learning (e.g. Greer, McElhinney, and Harris 1989; Fancourt 2009; ter Avest et al. 2009; Bender-Szymanski 2013; Iversen 2019), including - in France the value of debating about religion across the curriculum (Allieu-Mary 2007; Gaudin 2017). Such approaches are seen as encouraging students to organise their ideas and justify themselves, and are valued as a model for inter-religious learning. The role of textbooks in exemplifying reasons for claims has been considered by Newton and Newton (2006), finding them inadequate, and some research on questioning shows how it can support students' reasoning (e.g. Kerry 1980; Eke, Lee, and Cough 2005). Overall, in this theme, the process of discussion is seen as valuable for developing reasoning and for modelling democratic participation.

\section{Mixed-methods curriculum analysis}

To understand how the current curriculum addressed argumentation, we drew on other curriculum and policy analysis in RE (Hayward 2006; Fancourt 2015), and posed three research questions in the light of the literature review:

1. How often is argumentation identified in RE curriculum documents? This addresses the frequency of references.

2. What is the purpose of argumentation in the RE curriculum? This addresses the value of argumentation and reasoning, and what it contributes to the subject.

3. How is argumentation conceptualised in the RE curriculum? This explores different aspects of argumentation, including instructional features, and conceptions of progression. 
There is no single curriculum for RE in England, whereas since 1988 all other subjects have been included within a national curriculum. Since 1944, RE has been legally determined by local SACREs, through their Agreed Syllabus Committees, within a Locally Agreed Syllabus (LAS). Several national policy documents have been influential, but they are not statutory (Qualifications and Curriculum Authority 2004; Department for Children, Schools and Families 2010). For national examinations (GCSEs and A level), there are a range of examination boards. This variation means that it is difficult to establish common features across the country.

To cover this spread rigorously, we developed a mixed-methods approach. For the first question, we identified a sample of 35 LASs, and searched for the Boolean term 'argu-' to identify any explicit references to argumentation or related cognates. Agreed Syllabus Committees often collaborated, so these covered 49 local authorities, i.e. nearly a third of the total of 150 , across the nine official regions ${ }^{1}$. Most collaboration is local, e.g. Hampshire, Portsmouth, Southampton and the Isle of Wight (2016); some crossed regions, e.g. East Riding of Yorkshire, Hull City, North Lincolnshire and North East Lincolnshire. More eclectically, Bath and North East Somerset, Bristol, North Somerset, and the London Borough of Haringey worked together. Several commissioned an external agency, RE Today's Professional Services; thus, the Manchester, Oldham, Salford, Stockport, Tameside and Trafford LASs were almost identical, and similar to Leicestershire LAS, and Swindon LAS. The selection was both purposive in ensuring a range but also opportunistic in that some hyperlinks to electronic versions did not work, or we ordered physical copies but they did not arrive. The final selection of 35 LASs and our calculations are listed in Appendix 1.

\footnotetext{
${ }^{1}$ South West; London; South East; East Midlands; East of England; North East; West Midlands; North West; Yorkshire and Humberside
} 
To calibrate frequency of use we have compared the number of references per page, as a 'reference ratio' (RR). We recognise that the number of words per page is not uniform; whilst the ratio of reference to the total number of words would potentially be more accurate, this figure was hard to identify for physical documents as opposed to Word documents, and even in electronic format, diagrams and figures could be miscounted. Number of pages were unequivocal.

Research questions 2 and 3 examined argumentation in the LASs in a more fine-grained fashion because this concept can also be implicitly described by a range of other terms, such as explanation, reasoning or reflection. We selected a sub-sample of six LASs based on their demographic features and the origins of their agreed syllabus in order to reflect the diverse population as much as possible:

1. Hampshire, Portsmouth, Southampton, and Isle of Wight: covering a range of urban and rural settings, the LAS has an enquiry-based pedagogy (e.g. Erricker 2010; Hannam 2018) (Hampshire County Council 2016). The quantitative analysis showed 8 references over 122 pages - a low reference ratio $(\mathrm{RR})$ of 8:122; mean $=.07$.

2. Lambeth: an inner London borough with considerable ethnic and religious diversity (Lambeth Council 2015; based on 2005 version); across its 750 pages, it had a very low $\mathrm{RR}$ of $13: 750 ;$ mean $=.02$.

3. Leicestershire: around an historic East Midlands city, this is recognised as being the most diverse city in the country, and its agreed syllabus was drafted by RE Today's Professional Services (Leicestershire County Council 2016); RR 40:116; mean $=.34$.

4. Norfolk: including an historic city (Norwich) in the East of England, and a wide rural region, with both a historic Christian heritage and waves of recent Eastern European immigration (Norfolk County Council 2012); RR 13:64; mean $=.20$. 
5. Northumberland: Covered a more isolated region in the North East, with different patterns of ethnicity and religiosity, removed from the largest multi-religious cities. (Northumberland County Council 2016); RR 13:39; mean $=.31$.

6. Oxfordshire: including a small diverse South Eastern city and surrounding county, it drew upon the neighbouring Buckinghamshire LAS (Oxfordshire County Council 2015); RR 16:83; mean $=.31$.

Coding was in two phases. Initially, we individually coded the Leicestershire LAS, which used 'argu-' the most frequently, and then discussed the developing categories, to safeguard interanalyst reliability. Then we worked on different LASs individually, enriching the codes and categories, which were then collectively compared to ensure analytical stability. Our ethics of analysis was not to critique the LASs, but to identify broad trends across them. A further level of analysis could be to classify all the Boolean references according to the resultant codes, to identify how these words are used, but this would be time-consuming. Other limitations are that we have not included a survey of examination syllabuses, nor explored classroom practice; this is simply a robust review of the only legally mandated documentation.

\section{Frequency of references to argumentation}

On the first research question, there were no direct references to 'argumentation', but there were always references to 'argument[s]' and/or 'argue[s]', ranging from four (mean $=.03$ in Essex) to eighty-eight (mean $=.80$ in Dudley). However, the LASs varied in length, from 22 pages (Coventry and Warwickshire), to 750 (Lambeth). The ratio of references to pages ranged from the lowest at $2 \%($ Lambeth, 13 references over 750 pages, mean $=.02)$ to the highest at $80 \%$ (Dudley: $88 / 110$, mean $=.80)$, and the mean of all the 35 LASs was $.26(\mathrm{SD}=19.58)$, i.e.

roughly one reference every four pages. The mean references per LAS is 19.57 , i.e. there are 
around 19 references in any LAS. We therefore consider that argumentation is a common feature of variable frequency across RE in these 49 local authorities.

\section{Purposes of argumentation}

On the purposes of argumentation, using Toulmin as an analytical lens, two themes developed: expressing personal views in a democracy; epistemic and empathetic argumentation.

\section{Expressing personal views in a democracy}

One aim for RE was for students to 'express their own beliefs and ideas' (Lambeth 2015, 19), and to develop 'widely informed and detailed arguments about beliefs, ethics, values and issues, drawing well substantiated conclusions' (21). Norfolk, the LAS slightly below the overall mean on mentioning 'argu-' (2012), stated that RE enables students 'to think for themselves, to process information, reason, question and evaluate issues of truth, belief, faith and ethics' (4). This process of higher order thinking to support and justify one's individual stance appears indicative of how students are expected to engage with the subject and is congruent with TAP (see Figure 1).

However, the LASs specifically encouraged acknowledgement and respect for each other's views, rather than persuading others to adopt one's own views. 'RE does not seek to convert or urge any particular belief on pupils' (Leicestershire 2015, 2), and this is reflected in how students are to engage in argument: to consider one another's view but without being convincing or persuasive. The purpose of argumentation in RE is therefore the justification of stances, while persuasion is less emphasised. This is often motivated by another prominent purpose of RE: tolerance and recognition of plurality. For example, the programme for KS3 in the Norfolk Agreed Syllabus stipulated that:

pupils should take part in enquiries which enable them to investigate and explain why some people belong to faith communities and the reasons for diversity in religion 
(Norfolk 2012, 41).

Similarly, the KS3 aim in Oxfordshire Agreed Syllabus is to enable pupils to 'reflect on the benefits and challenges of living in a multi-faith and diverse society' $(2015,33)$. This emphasis on diversity and respecting different views was encapsulated by the explicit elements of argumentation. For example, 'to formulate reasoned opinion / argument [by] reflect[ing] on their own and others' responses, religious and secular' (32). Developing one's own view was often in the context of an understanding of the given fact of diversity of views.

Educating students to participate in a democratic society through dialogue was therefore a prominent objective, and fostered by engaging students in instructional activities using argumentation or debate,

In debating the fundamental questions of life, pupils learn to respect a range of perspectives. This contributes to learning about democracy, examining the idea that we all share a responsibility to use our voice and influence for the wellbeing of others

(Leicestershire 2016, 105).

The classroom becomes its own inter-faith and multi-religious context, and was assumed to be So,

pupils learn to think critically about their own and others' responses to ultimate questions in the light of other ideas and questions expressed in the class

(Oxfordshire 2015, 50).

This purpose of argumentation builds upon and is a step further from simply acknowledging diversity in society. Moreover, this is not the same as building socially shared knowledge (Kolstø and Ratcliffe 2008); here students learn to participate in a democratic society, through dialogue and by critically reflecting on and responding to arguments that conflict with their own, but they do not build epistemic agreement.

\section{Epistemic and empathetic argumentation}


Nevertheless, epistemic understanding was important: Norfolk required that 'pupils respond to, analyse and evaluate...the truth claims, beliefs and practices of different religions and worldviews, and the nature of religion itself' $(2012,24)$. Northumberland, with the RR above the overall mean, required that students think epistemically by 'explor[ing] some of the ultimate questions raised by human existence, making well-informed and reasoned personal responses, and expressing insights that draw on a wide range of examples including the arts, the media and philosophy' $(2016,35)$. Argumentation also offered opportunities for the critical interpretation of sacred texts, and Lambeth $(2015,12)$ required students to 'learn about sacred texts and...consider their meanings and interpretation'. However, because RE is presented as a multi-disciplinary field rather than a single discipline (Freathy et al. 2017), this necessitated an epistemic awareness of the underlying disciplines. For example, Northumberland LAS asked pupils to:

Explain and evaluate from different perspectives (e.g. that of an atheist, a sociologist, a theologian) dimensions of religions and worldviews which they encounter such as sources of authority, beliefs, practices and key values

(Northumberland 2016, 32).

Here, students are asked to adopt (at least) three positions to analyse a range of different traditions of belief.

Furthermore, an empathetic, perspective-taking approach required students to grasp the internal argumentation of different religions (Jackson 1997; 2004; Fancourt 2014); for instance, in understanding why believers hold a particular ethical position or belief, students must grasp the 'rules' of e.g. Buddhist ethics or Christian theology, which was often implicit in the issue of religious authority, e.g. Norfolk's (2012) area of study on 'teaching and authority: different sources of authority and how they inform people's beliefs, values and action' (p. 43), or the example above from Lambeth of sacred texts. Pupils may also be asked to adjudge the merits of these positions, e.g. by evaluating Buddhist vegetarianism or Christian teleological 
arguments (e.g. Lambeth), in which case they have to both grasp the internal theological or philosophical rules and any possible principles of their own, though balancing these rules or principles was unclear.

\section{Conceptualisation of argumentation}

Given these complex and challenging aims, the last research question reviewed how these aims are explicated, and three themes developed: field dependency and the nature of reasons; the lack of warrant and backing; progression.

\section{Field-dependency and the nature of reasons}

As noted, the aim of developing students' reasoning ability was unsurprisingly prevalent; for example, students had to apply 'reasoned argument to religious concepts' (Oxfordshire 2015, 34), but what should be considered as a 'reasoned argument' was unclear. Should claims be accepted if they are backed up by any reason, be it sensible or not? There was little discussion of how a 'reasoned argument' is deemed valid or coherent. Often, having set out RE as a multidisciplinary site, the field-dependent reasoning of each discipline was undefined, e.g. 'reasons for accepting or rejecting some explanations...including psychological and theological explanations' (Leicestershire 2016, 98). RE's own field-invariant elements over-reaching these disciplines were curiously vague and ran the risk of becoming either completely personal or a disciplinary mishmash.

The assumption that argumentation was the same across several disciplines exemplified the problem of the subject's intellectual model: without a clear epistemological boundary, what constitutes a claim and 'data' are unsettled. Moreover, a RE-specific field-invariant model was not specified, nor a generic cross-curricular field-invariant model indicated. Command words often invited argumentation but did not specify what was required. For example, when learning 
about Hinduism, students should 'attend to and explore personal experience of a number of visual illusions which raise questions about the nature of how things are' (Hampshire 2016, 51). However, as here, the meaning of verbs such as 'attend to', 'explore' or 'explain' in many LASs are neither obvious nor clearly differentiated from other command words, and may or may not involve argumentation. The absence of criteria encouraged uncontested interpretations, relying heavily on teachers' professionalism to be pedagogically effective. For example, how can students be supported to 'enquire into and explain some personal, philosophical, theological and cultural reasons for similarities and differences in religious beliefs and values, both within and between religions and worldviews' (Norfolk 2012, 41)? It is unclear what the differences in these 'reasons' are, and whether they follow the same operational processes when comparing religions and worldviews.

\section{The lack of warrant and backing}

Many of the instructional tasks and activities suggested by the LASs are constituted by Toulmin's elements of claims, evidence and rebuttals. Typically, this was a process of asserting a particular viewpoint (claim) with a reason (evidence), and then including another viewpoint (rebuttal), sometimes accounting for the other viewpoint in altering the original claim (qualifier). Activities such as 'debates and discussions' were suggested to 'prepare pupils for the fact that there will always be disagreement' and that 'their right of expression is balanced by a responsibility to listen' (Leicestershire 2015, 103), and some LASs encouraged the use of other structures and supports (e.g. Philosophy for Children, in Hampshire). These suggestions focus upon expressing and listening but press less on the quality of justification through warrant or backing. The debate structure provided a processual framework in which these elements might arise, but they were not set out clearly in the LASs.

\section{Vagueness in progression}


The lack of a conceptualisation of argumentation or a framework for judging its elements led to difficulties in describing progression. For example, Hampshire $(2016,82)$ defined the expectation of students 'to enquire' by the end of Year 9, 'they can give coherent, detailed explanations of a wider range of key concepts...and they can explain both more detailed connections as well as more subtle distinctions between concepts.' By the end of Year 10, 'to enquire' means 'students can interpret connections between a range of key concepts...They can give more complex explanations as to how concepts within a religion are related to one another' (83). The distinction between explaining 'more subtle distinctions between concepts' at Year 9 and 'more complex explanations' at Year 10 is arguably ambiguous and will rely on teachers' understandings of the appropriate elements and their interconnections.

\section{Conclusions}

In examining a representative range of LASs in England against Toulmin's model, we sought to delineate the frequency, purposes and conceptualisation of argumentation in the RE curriculum. Our findings suggest first that argumentation is commonly expected, indicated by approximately one reference in every four pages in the 35 LASs. Second, it serves several purposes, notably developing democratically competent students who are epistemically and empathetically flexible. We also found, however, that some components of argumentation (claim, rebuttal, and qualifier) are emphasised over others (evidence, warrant and backing). The etiquette of argumentation as social process is highly developed, with students able to oscillate between expression and attentiveness, but there were no established field-dependent or field-invariant criteria, and progression was therefore underspecified. Further, the objective of epistemically informed students may be undermined when there is an inadequate focus on the different evidence and warrants that underlie RE's inter-disciplinary perspective. The issue here is not about which discipline or paradigm should take precedence, but that whichever is 
chosen, the underlying argumentation will need development - the pedagogical implications of these choices need more nuanced development.

There are tensions of purposes here. The subject's pluralistic aims may account for the lack of explicit criteria: the ethos of acceptance and tolerance of multiple perspectives is understandably challenging to reconcile with the idea of evaluating arguments as better or worse. The goal of avoiding coercion is obviously agreeable and unlikely to meet objections, but may necessitate avoiding persuasive processes in the classroom, which will limit argumentative capacity, where students generate arguments for self-justification of their own stance rather than for persuading or convincing others. Ironically, the promotion of pluralism may hamper lively civil participation, by simply inviting the voicing of diverse views without critical depth. A more refined approach to justifying and evaluating arguments could more powerfully promote both participation in a plural society as well as students' epistemic and empathetic flexibility, and this provides a valuable intellectual space within the curriculum, since other subjects rarely offer such rich opportunities for such varied argumentation.

\section{Acknowledgements}

The authors acknowledge funding from the Templeton World Charity Foundation to OARS Project (Grant Number TWCF0238).

\section{References}

Allieu-Mary, Nicole. 2007. "Débats argumentés et laïcité en histoire-géographie. Pour une propédeutique à l'enseignement du fait religieux." [Argumentation debates in history- 
geography: towards an introduction to teaching facts about religion] Spirale - Revue de recherches en éducation 39:107-123.

Astley, Jeff and Francis, Leslie J. 2010 "Promoting positive attitudes towards science and religion among sixth-form pupils : dealing with scientism and creationism". British Journal of Religious Education 32 (3): 189-200. doi:10.1080/01416200.2010.498604

Ball, Deborah Loewenberg., and G. Williamson. McDiarmid. 1990. The subject-matter preparation of teachers. In Handbook of research on teacher education, edited by W. Robert Houston, Martin Haberman and John Sikula, 437-449. New York: Macmillian.

Basel, Nicolai, Ute Harms, and Helmut Prechtl. 2013. "Analysis of students' arguments on evolutionary theory." Journal of Biological Education 47 (4):192-199. doi: 10.1080/00219266.2013.799078.

Basel, Nicolai, Ute Harms, Helmut Prechtl, Thomas Weiß, and Martin Rothgangel. 2014. "Students' arguments on the science and religion issue: the example of evolutionary theory and Genesis." Journal of Biological Education 48 (4):179-187. doi: 10.1080/00219266.2013.849286.

Baumfield, Vivienne. 1996. Thinking through religious education. Cambridge: Chris Kington Publishing.

Bender-Szymanski, Dorothea. 2013. "Argumentation integrity in intercultural education: a teaching project about a religious-ideological dialogue as challenge for school." Intercultural Education 24 (6):573-591. doi: 10.1080/14675986.2013.845932.

Billig, Michael. 1996. Arguing and thinking: A rhetorical approach to social psychology. 2nd ed. Cambridge: Cambridge University Press.

Billingsley, Berry, Fran Riga, Keith S. Taber, and Helen Newdick. 2014. "Secondary school teachers' perspectives on teaching about topics that bridge science and religion." The Curriculum Journal 25 (3):372-395. doi: 10.1080/09585176.2014.920264.

Billingsley, Berry, Keith Taber, Fran Riga, and Helen Newdick. 2013. "Secondary School Students' Epistemic Insight into the Relationships Between Science and Religion-A Preliminary Enquiry." Research in Science Education 43 (4):1715-1732. doi: 10.1007/s11165-012-9317-y.

Conroy, James C., David Lundie, and Vivienne Baumfield. 2012. "Failures of meaning in religious education." Journal of Beliefs \& Values 33 (3):309-323. doi: 10.1080/13617672.2012.732812.

Conroy, James C., David Lundie, Robert A. Davis, Vivienne Baumfield, L. Philip Barnes, Tony Gallagher, Kevin Lowden, Nicole Bourque, and Karen Wenell. 2013. Does RE Work? A Multidimensional Investigation. London: Bloomsbury.

Cush, Denise. 1999. "The Relationships between Religious Studies, Religious Education and Theology: Big Brother, Little Sister and the Clerical Uncle?" British Journal of Religious Education 21 (3):137-146.

Department for Children, Schools, and Families. 2010. Religious education in English schools: Non-statutory guidance 2010. DSCF

https://assets.publishing.service.gov.uk/government/uploads/system/uploads/attachme nt_data/file/190260/DCSF-00114-2010.pdf

Eke, Richard, John Lee, and Nick Clough. 2005. "Whole-class interactive teaching and learning in religious education: transcripts from four primary classrooms." British Journal of Religious Education 27 (2):159-172. doi: 10.1080/0141620042000336648.

Erduran, Sibel, Liam Guilfoyle, Wonyong Park, Jessica Chan, and Nigel Fancourt. 2019. "Argumentation and Interdisciplinarity: Reflections from the Oxford Argumentation in Religion and Science Project." Disciplinary and Interdisciplinary Science Education Research 1 (8). doi: https://doi.org/10.1186/s43031-019-0006-9. 
Erduran, Sibel, and Maria Pillar Jiménez-Aleixandre, eds. 2008. Argumentation in science education: Perspectives from classroom-based research. Dordrecht: Springer.

Erduran, Sibel, Shirley Simon, and Jonathan Osborne. 2004. "TAPping into argumentation: Developments in the application of Toulmin's Argument Pattern for studying science discourse." Science Education 88 (6):915-933. doi: 10.1002/sce.20012.

Erricker, Clive. 2010. Religious Education: a Conceptual and Interdisciplinary Approach for Secondary Level. Abindon: Routledge.

Fancourt, Nigel. 2009. "The "safe forum": difference, dialogue and conflict." In Religious Education Research Through a Community of Practice Action Research and the Interpretive Approach, edited by J Ipgrave, R Jackson and K O'Grady. Münster: Waxmann.

Fancourt, Nigel. 2014. "Insiders and Outsiders: Task design in learning about religions,." In Designing Tasks in Secondary Education Enhancing Subject Understanding and Student Engagement. , edited by I. Thompson. London: Routledge.

Fancourt, Nigel. 2015. "Re-defining 'learning about religion' and 'learning from religion': a study of policy change." British Journal of Religious Education 37 (2):122-137. doi: 10.1080/01416200.2014.923377.

Freathy, Rob, Jonathan Doney, Giles Freathy, Karen Walshe, and Geoff Teece. 2017. "Pedagogical Bricoleurs and Bricolage Researchers: The case of Religious Education." British Journal of Educational Studies 65 (4):425-443. doi: 10.1080/00071005.2017.1343454.

Freathy, Rob, and Helen C. John. 2019. "Religious Education, Big Ideas and the study of religion(s) and worldview(s)." British Journal of Religious Education 41 (1):27-40. doi: 10.1080/01416200.2018.1500351.

Fuchs, Monika E. 2009. "Empirische und didaktische Perspektiven bioethischen Lernens im Religionsunterricht [Empirical and didactical perspectives of bioethical learning in religious education]." Theo-Web. Zeitschrift für Religionspädagogik [Theo-Web. Journal for Religious Education] 8 (1):80-90.

Gaudin, Philippe. 2017. "Neutrality and impartiality in public education: the French investment in philosophy, teaching about religions, and moral and civic education." British Journal of Religious Education 39 (1):93-106. doi: 10.1080/01416200.2016.1218221.

Gearon, Liam. 2013. On Holy Ground: The Theory and Practice of Religious Education. Abingdon: Routledge.

Goldman, Ronald. 1965. Readiness for religion. London: Routledge.

Goldman, Susan R., Mon-Lin M. Ko, Cynthia Greenleaf, and Willard Brown. 2018. "Domain-Specificity in the Practices of Explanation, Modeling, and Argument in the Sciences." In Scientific Reasoning and Argumentation: The Roles of Domain-Specific and Domain-General Knowledge, edited by Frank Fischer, Clark A. Chinn, Katharina Engelmann and Jonathan Osborne. London: Routledge.

Gottlieb, E. 2001. Religious thinking in childhood and adolescence: Argumentative reasoning and the justification of religious belief. Unpublished Ph.D. thesis, The Hebrew University, Jerusalem.

Gottlieb, Eli, and Mandel Leadership Institute. 2007. "Learning How to Believe: Epistemic Development in Cultural Context." Journal of the Learning Sciences 16 (1):5-35. doi: 10.1080/10508400709336941.

Greer, J. E., E. P. McElhinney, and J. E. Harris. 1989. A Study of Classroom Discussion in Religious Education. British Journal of Religious Education 11 (2):92-102. doi: 10.1080/0141620890110206. 
Gutmann, Amy, and Sigal Ben-Porath. 2015. "Democratic education." In The Encyclopedia of political thought, edited by Michael T. Gibbons. Chichester: Wiley Blackwell.

Hampshire County Council. 2016. The Agreed Syllabus for Hampshire, Portsmouth, Southampton and the Isle of Wight. Hampshire: Hampshire County Council.

Hanley, Pam, Judith Bennett, and Mary Ratcliffe. 2014. "The Inter-relationship of Science and Religion: A typology of engagement." International Journal of Science Education 36 (7):1210-1229. doi: 10.1080/09500693.2013.853897.

Hannam, Pat. 2018. Religious education and the public sphere. London: Routledge.

Hayward, Mary. 2006. "Curriculum Christianity." British Journal of Religious Education 28 (2):153-171. doi: 10.1080/01416200500531894.

Hella, Elina, and Andrew Wright. 2009. "Learning 'about' and 'from' religion: phenomenography, the Variation Theory of Learning and religious education in Finland and the UK." British Journal of Religious Education 31 (1):53-64. doi: 10.1080/01416200802560047.

Helm, Paul. 2003. Faith with reason. Oxford: Oxford University Press.

Hookway, Susanna. 2002. "Mirrors, Windows, Conversations: Religious Education for the Millennial Generation in England and Wales." British Journal of Religious Education 24 (2):99-110. doi: 10.1080/0141620020240204.

Iversen, Lars Laird. 2019. "From safe spaces to communities of disagreement." British Journal of Religious Education 41 (3):315-326. doi: 10.1080/01416200.2018.1445617.

Jackson, Robert. 1997. Religious education: an interpretive approach. London: Hodder \& Stoughton.

Jackson, Robert. 2004. Rethinking religious education and plurality. London: RoutledgeFalmer.

Jackson, Robert, and Judith Everington. 2017. "Teaching inclusive religious education impartially: an English perspective." British Journal of Religious Education 39 (1):724. doi: 10.1080/01416200.2016.1165184.

Joshi, Parag. 2016. "Argumentation in Democratic Education: The Crucial Role of Values." Theory Into Practice 55 (4):279-286. doi: 10.1080/00405841.2016.1208066.

Kerry, Trevor. 1980. "The Demands Made by RE on Pupils' Thinking." British Journal of Religious Education 3 (2):46-52, 65. doi: 10.1080/0141620800030203.

Kienpointer, M. 1983. Argumentationsanalyse [Argumentation Analysis] Insbruck: Verlag des Institutes für Sprachwissenschaft Universität Innsbruck.

Kuhn, Deanna. 1993. "Science as argument: Implications for teaching and learning scientific thinking." Science Education 77 (3):319-337.

Lambeth Council. 2015. Lambeth Agreed Syllabus for Religious Education. Lambeth: Lambeth Council.

Leicestershire County Council. 2016. Leicestershire religious literacy for all: The agreed syllabus for religious education 2016-2021. Leicestershire: Leicestershire County Council.

McClintock, Sarah L. 2010. Omniscience and the Rhetoric of Reason: Śantarakșita and Kamalaśilla on Rationality, Argumentation, and Religious Authority. Boston: Wisdom Publications.

Newton, L. D., and D. P. Newton. 2006. "Can explanations in children's books help teachers foster reason-based understandings in religious education in primary schools?" British Journal of Religious Education 28 (3):225-234. doi: 10.1080/01416200600811311.

Norfolk County Council. 2012. The Norfolk Agreed Syllabus for Religious Education 2012. Norfolk: Norfolk County Council. 
Northumberland County Council. 2016. Agreed Syllabus for Religious Education 2016. Northumberland: Northumberland County Council.

Organisation for Economic Co-operation and Development. 2018. The future of education and skills: Education 2030. OECD

https://www.oecd.org/education/2030/E2030\%20Position\%20Paper\%20(05.04.2018). pdf

Oxfordshire County Council. 2015. The Oxfordshire Agreed Syllabus for Religious Education 2015 - 2020. Oxfordshire: Oxfordshire County Council.

Pearce, Jo, Alexis Stones, Michael J. Reiss, and Tamjid Mujtaba. 2019. "'Science is purely about the truth so I don't think you could compare it to non-truth versus the truth.' Students' perceptions of religion and science, and the relationship(s) between them: religious education and the need for epistemic literacy." British Journal of Religious Education:1-16. doi: 10.1080/01416200.2019.1635434.

Pontecorvo, Clotilde, and Hilda Girardet. 1993. "Arguing and Reasoning in Understanding Historical Topics." Cognition and Instruction 11 (3-4):365-395. doi: 10.1080/07370008.1993.9649030.

Qualifications and Curriculum Authority. 2004. Religious Education: The Non-statutory National Framework. London: QCA.

Reed, Esther D., Rob Freathy, Susannah Cornwall, and Anna Davis. 2013. "Narrative theology in Religious Education." British Journal of Religious Education 35 (3):297312. doi: 10.1080/01416200.2013.785931.

Rex, Lesley A., Ebony Elizabeth Thomas, and Steven Engel. 2010. "Applying Toulmin: Teaching Logical Reasoning and Argumentative Writing." The English Journal 99 (6):56-62.

Schmidt, Hiemke K., Dietmar Grube, and Martin Rothgangel. 2017. "The Relevance of Prior Content Knowledge Regarding Bioethical Dilemmas: Religious Education in Dialogue with Empirical Studies of Educational Psychology." 30 (1):68. doi: https://doi.org/10.1163/15709256-12341350.

Schmidt, Hiemke, Martin Rothgangel, and Dietmar Grube. 2015. "Prior knowledge in recalling arguments in bioethical dilemmas." Frontiers in Psychology 6 (1292). doi: 10.3389/fpsyg.2015.01292.

Shulman, Lee S. 2008. "Pedagogies of Interpretation, Argumentation, and Formation: From Understanding to Identity in Jewish Education." Journal of Jewish Education 74 (sup1):5-15. doi: 10.1080/15244110802493289.

Simpson, Jane Mary Ramsay. 2012. "Bridging the gap between Religious Education and gifted education: theory and praxis in three secondary school programmes in Cambridgeshire." British Journal of Religious Education 34 (3):247-261. doi: 10.1080/01416200.2011.649342.

Smart, Ninian. 1989. The World's Religions. Cambridge: Cambridge University Press.

Staples, Megan, Jill Newton, and Dorothea Anagnostopoulos. 2016. "This Issue." Theory Into Practice 55 (4):275-278. doi: 10.1080/00405841.2016.1222155.

Teece, Geoff. 2011. "Too many competing imperatives? Does RE need to rediscover its identity?" Journal of Beliefs \& Values 32 (2):161-172. doi: 10.1080/13617672.2011.600815.

ter Avest, Ina, Dan-Paul Jozsa, Thorsten Knauth, Javier Rosón, and Geir Skeie (eds). 2009. Dialogue and Conflict on Religion. Studies of Classroom Interaction in European Countries. Munster: Waxmann.

Thwaites, Helen. 2005. "Can 'philosophy for children' improve teaching and learning within attainment target 2 of religious education?" Education 3-13 33 (3):4-8. doi: $10.1080 / 03004270585200261$. 
Toulmin, Stephen. 1958. Uses of Argument. Cambridge: Cambridge University Press.

Wallbridge, J. 2011. God and logic in Islam: the caliphate of reason. Cambridge: Cambridge University Press.

Walton, Douglas. 1996. Argumentation Schemes for Presumptive Reasoning. Mahweh, NJ: Lawrence Erlbaum Associates.

Weiß, Thomas. 2016. Fachspezifische und fachübergreifende Argumentationen am Beispiel von Schöpfung und Evolution. [Specialist and multidisciplinary Arguments Using the Example of Creation and Evolution]. Gottingen: V\&A.

Zembal-Saul, Carla, Danusa Munford, Barbara Crawford, Patricia Friedrichsen, and Susan Land. 2002. "Scaffolding Preservice Science Teachers' Evidence-Based Arguments During an Investigation of Natural Selection." Research in Science Education 32 (4):437-463.

Zohar, Anat, and Ali Ben David. 2008. "Explicit teaching of meta-strategic knowledge in authentic classroom situations." Metacognition and Learning 3 (1):59-82. 